\title{
CALEIDOSCOPIOS DE AMOR EN LA MÍSTICA FEMENINA MEDIEVAL: BEATRIJS VAN NAZARETH Y HADEWIJCH
}

\author{
Blanca Garí \\ Universidad de Barcelona, Barcelona, España \\ gari@ub.edu
}

\section{RESUMEN / ABSTRACT}

Este artículo tiene por objetivo mostrar a través del análisis de dos textos de dos místicas neerlandesas del siglo XIII, Beatrijs van Nazareth y la beguina de Amberes Hadewijch, los nuevos caminos emprendidos por la mística femenina del siglo XIII que llevan a la fusión de la escalera de las virtudes, los itinerarios de perfección y las formas de encuentro amoroso con la divinidad. Frente a una topografía ascensional que transcurre por un cierto número de grados, propia de las imágenes tradicionales de la escalera, se recurre aquí a la imagen del caleidoscopio para comprender el carácter circular de las nuevas aproximaciones y la necesidad de entender los itinerarios de perfección en concordancia con las nuevas prácticas espirituales de la mística amorosa.

Palabras clave: mística femenina, nuevo misticismo, itinerario de perfección, escalera, caleidoscopio.

KALEIDOSCOPES OF LOVE IN MEDIEVAL FEMALE MYSTICISM: BEATRIJS VAN NAZARETH AND HADEWIJCH

This paper aims to show, through the analysis of two texts by two Dutch mystics of the thirteenth century, Beatrijs van Nazareth and Hadewijch, the beguine from Ambers, the new paths undertaken by thirteenth-century female mysticism. These paths lead to the fusion of the stairway of virtues, the itineraries of perfection, and the ways of amorous encounter with the divinity. Confronting a fundamentally ascensional topography that goes through a certain number of levels, which is typical of the traditional imagery of the stairway, this paper turns to the image of the kaleidoscope to understand the circular character of these new approaches and the need to understand the itineraries of perfection in concordance with the new spiritual practices of amorous mysticism. 
KEYWORDS: Female mysticism, new mysticism, itineraries of perfection, stairway, kaleidoscope.

"No existe un desarrollo lineal, sólo existe la circunvalación del uno mismo". (Jung 204)

El símbolo de la escalera se encuentra profundamente inscrito en la tradición de los itinerarios espirituales de perfección. De forma particular, muchos textos de la mística antigua y medieval recurren a una topografía ascensional que transcurre por un cierto número de grados o escalones y cuyo referente primero, partiendo del sueño de Betel y la escalera de Jacob, es la Scala Paradisi de Iohannes Climacus (Heck 19-29). Los estudios contemporáneos lo han subrayado con frecuencia y han analizado la escalera de perfección y sus manifestaciones en la patrística, en la tradición monástica y en la mística (Heck). Se trata indiscutiblemente de un lugar común, rico y complejo, en la historia del cristianismo y en el bagaje de las imágenes relacionadas con la idea de un "progreso" del alma hacia Dios (Acosta-García y Serra Zamora 257 ss.). Pero no es la única ni se presenta siempre de forma unívoca. Con frecuencia, la de la escalera es una imagen que se ve desbordada y completada por otras de carácter también ascensional o incluso invadida por la potencia simbólica del descenso (Garí 222). Este es el caso de los textos del llamado "nuevo misticismo" o de la "mística femenina"1, los cuales, en general, se muestran especialmente ricos en expresiones de progreso espiritual y en la presentación de nuevas fórmulas que buscan poner en palabras caminos hacia el encuentro con lo divino (McGinn 12ss.; Cirlot y Garí, Mirada Interior

1 Utilizaré en este estudio ambos conceptos "nuevo misticismo" y "mística femenina". El de "nuevo misticismo" acuñado por Bernard McGinn define las corrientes protagonizadas por una mística vernácula nacida en torno a 1200 en la que las mujeres jugaron un papel preponderante. "Mística femenina" señala precisamente esa preponderancia así como el hecho de que fue a partir de los primeros textos de las místicas del siglo XIII cuando lo "femenino" inundó de forma general el ámbito de la mística medieval trascendiendo las fronteras de género y hallándose presente tanto en mujeres como en hombres (Cirlot y Garí, Con Tact). 
13-14). En particular, los textos de la mística femenina, representada a lo largo del siglo XIII por autoras como Hadewijch, Beatrijs van Nazareth, Mechthild von Magdeburg, Ángela da Foligno o Marguerite Porete, aunque contienen en distintos grados imágenes de la escalera, recurren con frecuencia a interpretaciones complejas de la misma o a formas complementarias, así como a nuevas formulaciones simbólicas, con otros sistemas de referencia y otras imágenes. Por ejemplo, precediendo las nuevas expresiones de la mística femenina del siglo XIII, la escalera de las virtudes de Hildegard von Bingen remitía ya a nuevas imágenes como la de la montaña y la de la columna (Cirlot, "La Ciudad celeste" 490; Acosta-García y Serra Zamora 258). Pero sobre todo a partir de 1200 el itinerario de perfección forjado en la práctica de las virtudes se funde irremisiblemente con la experiencia de amor y de unión con la divinidad. Los siete "modos" de Beatrijs van Nazareth, las doce "horas innombrables" de Hadewijch, los "siete estados" de Marguerite Porete, los "treinta" y luego "siete pasos" de Ángela da Foligno, o las múltiples enumeraciones de "formas", "clases" o "cosas" en la obra de Mechthild son algunos de las nuevos enunciados con los que la imagen de la escalera, sin ser necesariamente abandonada, se ve desbordada al poner en palabras la experiencia de un itinerario espiritual.

Explorar en su conjunto esas nuevas fórmulas, establecer comparaciones, espacios comunes y diferencias es un reto que este trabajo no pretende abordar. Propongo aquí, en cambio, abrir una ventana para atisbar posibles vías de reflexión y acercamiento al tema, a través del análisis concreto de un doble ejemplo de la primera mitad del siglo XIII: por un lado, el pequeño tratado dedicado a los siete modos de Amor, Van seuen manieren van heileger minnen, de Beatrijs van Nazareth ${ }^{2}$ y por otro, la carta XX que la beguina de Amberes Hadewijch, dedica a las doce horas innombrables de Amor, de xij onghenoemde vren der Minnen ${ }^{3}$. En el primer caso se trata del texto de una monja cisterciense y priora de la comunidad de Nazareth de la cual conservamos una hagiobiografía, la Vita Beatricis, escrita en latín y construida muy pocos años después de su muerte por el capellán del monasterio sobre la base de

En el presente artículo citaré esta obra desde la edición de Léonce Reypens en Jozef van Mierlo de 1926, en la versión on-line de 2011 DBNL http://www.dbnl.org/tekst/ beat0011rey01_01/beat0011rey01_01_0003.php

En el presente artículo citaré esta obra desde la edición de Jozef van Mierlo de 1947, en la versión on-line de 2011 DBNL 2003, páginas 170-175. http://www.dbnl.org/tekst/ hade002brie01_01/colofon.htm 
los escritos de la propia monja; unos escritos, redactados en el neerlandés materno de Beatrijs, de los que solo conservamos este pequeño tratado. El segundo texto pertenece a la beguina Hadewijch, de la que poseemos una importante y diversificada obra, toda ella en neerlandés medieval y compuesta de cartas, poemas y un libro de visiones; la carta XX forma parte del conjunto de su correspondencia, pero por su estructura y forma se trata en realidad, o al mismo tiempo, de un breve tratado sobre lo que casi podríamos llamar, una vez más, "modos de Amor".

Abordar este doble ejemplo de manera comparativa ofrece la ventaja de mostrar dos soluciones diferentes pero contemporáneas, geográficamente muy cercanas, escritas en la misma lengua y que intentan responder ambas a la necesidad de comprender los itinerarios de perfección en concordancia con las nuevas prácticas espirituales de la mística amorosa. Se trata pues de analizar dos textos cronológicamente tempranos que nos pueden guiar por los caminos emprendidos por el nuevo misticismo y poner sobre la pista del proceso que lleva a la fusión de la escalera de las virtudes los itinerarios de perfección y las formas de encuentro amoroso con la divinidad.

En un breve capítulo dedicado a la figura de Beatrijs van Nazareth, Alois Maria Haas apuntaba hace años una idea que creo que puede servir de guía en este estudio. Escribía allí Haas para referirse a los "modos de Amor": "Psychologisch könnte es durchaus sein, dass die verschiedenen Stufen nicht nacheinander, sondern in verschiedener Weise durcheinander sich vollziehen: ein Kaleidoskop der Minneerfahrung" (396). "Psicológicamente podría ser muy bien que los diferentes grados no tengan lugar sucesivamente sino mezclados sin distinción: un calidoscopio de la experiencia de Amor". Y es que efectivamente, si bien los diferentes modos -o escalones- de la experiencia de Amor descritos en el tratado de esta mística cisterciense son divergentes y nos hablan de experiencias diversas del alma, es necesario comprender que no estamos propiamente ante una escalera, ni ante un itinerario lineal que despliega las etapas de una vida. Aunque, eso sí, estamos ante un itinerario que deberemos esforzarnos en comprender de una forma nueva (Cirlot y Garí, La mirada interior 123). Para hacerlo, la expresión "caleidoscopio de Amor" me parece especialmente oportuna. Un caleidoscopio es un artefacto que sirve para observar imágenes bellas ${ }^{4}$ y que se compone de un tubo que contiene varios espejos en ángulo, formando una especie de prisma, con su

$4 \quad$ Del griego kalós: “bella”; éidos: “imagen”; y scopéo: “observar”. 
parte reflectante hacia el interior y al extremo de los cuales se encuentran láminas traslúcidas entre las que hay varios objetos de color y forma diferentes, cuyas imágenes se ven multiplicadas simétricamente al ir girando el tubo mientras se mira por el extremo opuesto. Yo creo que acercarnos a los textos de la mística femenina con la idea de enfocar la mirada haciendo girar sus imágenes, -llenas por lo demás de belleza y fuerza poética- puede enseñarnos a verlas de forma más apropiada.

Recorramos desde esta perspectiva en primer lugar el tratado de la propia Beatrijs van Nazareth que Haas define como Kaleidoscop. El tratado da comienzo con una afirmación circular y contundente: "S'Euen manieren sijn van minnen, die comen vten hoegsten ende $<$ keren $>$ weder ten ouersten", (Beatrijs 3, lin. 3-4) "Hay siete modos de amor que vienen de lo más alto y retornan de nuevo a lo superior" . Las primeras líneas del texto de Beatrijs no pueden ser más elocuentes. La formulación perfecta del lazo neoplatónico de la salida y regreso a Dios, enunciado de forma tradicional y original al mismo tiempo en la frase que encabeza el tratado, da cuenta tanto de su carácter de itinerario como de su estructura circular. Es interesante contrastar este acotado comienzo con el texto de la "traducción" al latín que del mismo hiciera unos años más tarde el capellán de Nazareth, al colocar el tratado hacia el final del tercer libro de su hagiobiografia. Escribe allí el capellán:

Sunt igitur hij dilectionis gradus sive status septem numero: per quos ad dilectum suum, non equalibus quidem passibus, sed nunc vy pedibus incedendo, nunc cursu velocissimo properando, nonnumquam etiam, sumptis agilitatis penis, pernicius evolando, pervenire promeruit. (Vita Beatricis 158, lin. 10-19)

Estos pues son los siete grados o estados de amor, siete en número, a través de los que ella mereció alcanzar a su amado no a pasos regulares, sino ora caminando a pie, ora corriendo veloz, o incluso volando con ágiles alas.

Es evidente que el traductor interpreta la primera frase del tratado como la expresión tradicional de un itinerario de vida concreto, el de una monja destinada a un proceso ascendente de perfección. La Vita encarna la revelación,

5 En todos los casos, tanto para los textos de Hadewijch como para el tratado de Beatriz, se citará la versión original de los textos medievales acompañada de una traducción que ofrece una versión propia sobre la base del original y a las diversas traducciones existentes. 
la transforma en etapas, grados, escalones de una experiencia de vida desplegada linealmente hacia la perfección, una experiencia que imprime en el cuerpo de Beatrijs los signos visibles de su santidad (A. Hollywood 1995). En contraste con ello, Beatrijs abre su itinerario trazando un rápido círculo y a partir de él, como si se tratara de un caleidoscopio que girase vertiginosamente, despliega las distintas facetas de un prisma que revela los diversos modos y experiencias de Amor.

El primer modo, en el decir de Beatrijs, es "ene begerte die comt werkende uter minnen,[...] die sekerlike compt vter minnen" (Beatrijs 3 lin. 11), "un deseo activo de amor [...] que procede del propio Amor". Este deseo empuja al alma a vivir en la pureza, en la nobleza y en la libertad en la que el Creador la ha hecho a su imagen y semejanza. A este modo corresponde el autoconocimiento, la indagación en el interior de sí y de su corazón en perfecta concordancia con la idea de origen cisterciense -formulada por Bernard de Clairvaux y desarrollada ampliamente por la comunidad femenina de Helftade la concentración de toda espiritualidad en el corazón, sea de Cristo sea de las criaturas humanas (Spitzlei; Haas 393): "ende an hare te treckene ende te behoudene al dat hare helpen mach ende vorderen ter minnen" (Beatrij 6, lin. 41-43), "su corazón no descansa ni ceja jamás de buscar, reclamar, aprender, atrayendo hacia sí y guardando consigo cuanto pueda ayudarle a avanzar en el amor".

El segundo modo presenta, en el tratado de Beatrijs, la naturaleza totalmente desinteresada y gratuita del amor, "sonder enich waeromme", el amor "sin porqué". En este segundo modo, este amor sin porqué se explica mediante una imagen también famosa, la de la doncella que sirve a su Señor sin buscar recompensa:

dat es, datsi ondersteet onsen here te dienne te uergeues, allene met minnen · sonder enich waeromme ende sonder eneghen loen van gratien ofte van glorien · ende also gelijc alse i Jonfrouwe die dient haren here van groter minnen. (Beatrijs 7, lin. 2-7)

A veces [el alma] tiene otro modo de amor, en el que emprende la tarea de servir a nuestro Señor de manera totalmente gratuita, sólo con amor, sin un porqué, sin recompensa de gracia o gloria; como una noble doncella que se emplea al servicio de su señor por puro amor.

La gratuidad del Amor es un concepto destinado a una larga vida en la tradición de la escritura mística; además de Beatrijs recoge la misma idea su contemporánea Hadewijch, y la expresión "sin porqué" es utilizada por 
Hadewijch II, Marguerite Porete, Meister Eckhart, Heinrich Seuse y tantos otros representantes de la mística de los siglos posteriores. En todos ellos, no se trata tanto de una etapa de vida o un momento concreto en el camino de perfección, sino sobre todo de una entre las imágenes que verbalizan la experiencia de acercamiento a la divinidad y el juego amoroso que conduce a la unión.

El tercer modo de Beatrijs es el sufrimiento, la tortura de amor que padece el alma que no puede satisfacer plenamente su deseo de servir a Dios de manera perfecta, a causa de su naturaleza creada:

Dese begerte wert onderwilen seere versto remt 'in der zielen, 'ende so begrijpt si met starker begerten alle dinc te doene ende alle dogen te volgene 'al te dogene ende te verdragene "ende al har werke sonder sparen ende sonder mate in der minnen te volgene. (Beatrijs 9-10, lin. 8-13)

Este deseo sacude con violencia el alma que, con pasión, se esfuerza hacerlo todo, alcanzar toda virtud, sufrir o soportar todo y cumplir todas sus obras en el amor, sin medida ni consideración.

El intento imposible es el infierno: "Ende so es hare alse of si al leuende steruet · ende steruende die pine van der hellen $<$ gevoelt $>$; ende al hare leuen es hellechtich" (Beatrijs 12 1. 47-49), "Y así le parece que muere viviendo y muriendo sufre el infierno. Toda su vida es infernal". En pocas palabras, el tema de la necesaria muerte en vida y de la experiencia mística del exilio, esto es, del infierno, aparece aquí perfectamente formulado (Haas 394). El infierno y la vida infernal serán también temas centrales en la obra de su contemporánea Hadewijch. Al punto que, en uno de sus poemas de rima mixta, "Infierno"(helle) constituye uno, y el más alto, de los siete nombres que se otorga a Amor (Hadewijch, Mengeldichten XVI, 84). El tema de la muerte en vida y el de la "vida infernal", levende helsche, aparece asimismo en la visión V (Hadewijch, Visioenen, V 61, lin. 49), así como en otros textos de la beguina.

El cuarto modo es para Beatrijs la experiencia del abismo de amor en el que el alma se sumerge por igual en el gozo y el dolor, en una perfecta coincidencia de opuestos que la desborda y convierte en amor mismo.

N'och pleget onse here ander maniere te gheuene uene van minnen 'ende selcstont in groter waelheiden selcstont in groter welegheiden 'Ende dan ghevuelt si dat al hor sinne sijn geheilicht in der minnen 
ende har wille es worden minne · 'ende datsi so diepe es versonken ende verswolgen int afgront der minnen · ende selue al es worden minne. (Beatrijs 13-14, lin. 1-4 y 21-26)

Cuarto modo de Amor. Nuestro Señor acostumbra a procurar otros modos de amor, ya en grandes delicias, ya en grandes penas. [...] siente entonces todos sus sentidos santificados en amor y su voluntad transformada en amor, $y$ tan profundamente se sumerge y es absorbida en el abismo de amor que ella misma ya no es sino amor.

Beatrijs toma así la noción del "abismo de amor" de la tradición latina y la utiliza, junto con Hadewijch, por primera vez en la mística femenina para hablar de la experiencia de la unión con Dios.

El quinto modo de Beatrijs es la tormenta o furia de amor orewoet, tema central en las cartas y poemas de su coetánea Hadewijch. En él, la locura y violencia del amor afectan al cuerpo y al alma indisociablemente, al tiempo que el abrazo de amor la fortalece. En el quinto modo, escribe:

die minne in der zielen starkeleke verwecket wert · "ende stormeleke op-ersteet met groten geruse ende met groter verwoetheit · 'alse oft si met gewout therte seere breken · ende sele trecken vut hare seluen ende bouen har seluen in die ufeninghe van minnen. ende int gebreken der minnen. [...] Alsi hier in es so es si so starc in den geeste 'ende vele begripende in therte, ende vromeger an dien lichame $\cdot$ ende spoedeger in den werken, ende seere doende van buten ende van binnen - 'so dat hare seluen dunct, dat al werket - "ende onledich es dat an hare es · al es si oec al stille van buten. (Beatrijs 13-14, lin. 2-8 y 18-24) amor se despierta en el alma como una tempestad, con gran estrépito y gran furor y parece como si el corazón fuera a quebrarse por la fuerza del asalto y el alma hubiera de salir de sí misma en la entrega al amor y en su irrupción [...] Cuando se halla en este estado, [el alma] se encuentra tan fuerte de espíritu, abraza tantas cosas en su corazón, siente tal fortaleza en su cuerpo, es tan ágil en sus actos, tan activa interior y exteriormente, que todo en ella, según le parece, es ocupación y trabajo, al mismo tiempo que su cuerpo permanece en calma.

La violencia, sin embargo, prevalece: "'Ondertusschen so wert minne so onghemate ende so ouerbrekende in der sielen. 'alse har seluen so starkeleke - 'ende so verwoedelike < berurt> int herte, dat hare dunct, dat har herte menichfoudeleke wert seere gewont” (Beatrijs 19-20, lin. 33-40). "A instantes 
el amor pierde en ella hasta tal punto la medida, brota con una tal vehemencia y agita el corazón con tal fuerza y tan furiosamente que éste parece herido por todos lados".

Amor hiere renovadamente -escribe Beatrijs- hasta que su corazón es atravesado por una flecha: "Si gevuelt oec die wile, dat een gescutte geet dicwile dor har herte toter kele ende vort toten hersenen 'alse of si hars sins gemissen soude" (Beatrijs 20, lin. 46-49). "Otras veces es como una flecha que atraviesa su corazón hasta la garganta y más allá hasta el cerebro y le hace perder el sentido". La "herida de amor", tematizada en estas líneas, enraizada claramente en el Cantar de los Cantares, constituye otro de los conceptos clave de la mística femenina destinado a perdurar en la tradición de Occidente. En esta desmesura se instala la paradoja: "ende dat hare < dipst> sleet die wonde "dat geuet hare allene ghesunde" (Beatrijs 23, lin. 79-80). "Lo que más la aflige y la atormenta es lo que más la cura y la consuela; lo que más profundamente la hiere, es su única salud". Hadewijch, como se verá, volverá sobre el mismo tema.

El sexto modo parece contraponerse en paralelo al quinto. La tormenta de amor se ha transformado en un estado de reposo absoluto. "So geuult si noch andre maniere van minnen, in naerren wesene ende in hogeren bekinne" (Beatrijs 23, lin. 23-45). "El alma experimenta entonces otro modo de amor con un conocimiento más íntimo y elevado", pues Amor triunfa sobre sus faltas, domina sus sentidos, la hace dueña de sí misma, experimentando entonces " "ende ene clare purheit. "ende ene geestelike sutheit, ende ene begerlike vriheit. 'ende ene onderscedege wijsheit, ende ene sachte effenheit $<$ tonsen here ende een nakenisse van> gode" (Beatrijs 24, lin. 20-24), "una potencia divina, una pureza límpida, una suavidad espiritual, una libertad ferviente, un sabio discernimiento, una dulce igualdad con nuestro Señor y un conocimiento íntimo de Dios".

Beatrijs introduce entonces dos famosas metáforas que expresan el estado de libertad con la que su espíritu "vaga" en Amor y que tendrán resonancias en otros textos del nuevo misticismo: la del ama de casa que dispone de ella libremente según su agrado y la del pez que nada en libertad o el pájaro que vuela audaz en las alturas. Finalmente escribe: "Dan maectse minne so coene ende so vri, datsi en ontsiet noch // menschen noch viant. "noch ingel noch heilegen· noch gode selue" (Beatrijs 27, lin. 52-54). "Quien ha triunfado en ese modo se ha hecho tan audaz que no teme ni hombre ni demonio, ni ángel ni santo, ni a Dios mismo." Con estas palabras Beatrijs parece llegar a 
la conclusión de su tratado, que se reabre, sin embargo, en el séptimo modo de Amor.

En el séptimo modo, de alguna forma Beatrijs recapitula. Cada una de las facetas de su prisma, cada uno de los modos de Amor ya descritos, parecen asomar en el. El séptimo es todos y a la vez superior a todos los modos anteriores, porque en él la experiencia de Dios se expresa por encima de todo lo humano y por encima del tiempo:

N'och heuet die salege ziele ene maniere van hoger minnen, die hare niet luttel <wercs $>$ geuet van binnen, 'dat es, datsi es getrect bouen menschelicheit in minnen, ende bouen mensceliken sin ende redene, ende bouen alle die werke on herten, 'ende allene es getrect met eweliker minnen in die // ewelicheit der minnen. 'ende in die $<$ onbegriplicheit, in die witheit>, ende die <ongerinlike> hoecheit. 'ende in die diepe afgronde der godheit, die es al in alle dinc. 'ende die onbegripelec bliuet bouen alle dinc. "ende die es onwandelec, al-wesende, al-mogende' al-begripende 'ende al-geweldeleke werkende [...] 'aldus es si geclommen met geeste- bouen den tijt in die ewelicheit <ende es gehoght bouen die gigten van minnen in die ewelicheit> der minnen die es sonder tijt. (Beatrijs 28-29, lin. 2-14) El alma bienaventurada conoce todavía un séptimo modo de amor sublime, que opera en ella interiormente un singular trabajo: es atraída por amor por encima de su humanidad, por encima de la razón y de los sentidos humanos, por encima de toda obra de nuestro corazón; atraída por el mero amor eterno en la eternidad del amor, en la ininteligibilidad, en la anchura y altura inaccesibles y en el profundo abismo de la Deidad que es todo en todo y que permanece incognoscible por encima de todo, inmutable, todo ser, todo poder, todo inteligencia, todo obra soberana. [...] Y es así como, elevada en espíritu por encima del tiempo, en la eternidad, por encima de los dones de amor, que está fuera del tiempo, por encima de todos los modos humanos de amar y, en su deseo de trascendencia, por encima de su propia naturaleza.

En este séptimo modo, el alma participa del conocimiento y posesión celestes de Amor y se halla en el corazón de los ángeles de fuego. Pero la paradoja se mantiene, pues abismada en Amor vive en el exilio, el tema de la muerte en vida reaparece: "“Ay heilege begerte der minnen· wie staerc es uwe cracht in der <minnender $>$ sielen! Het es ene salige passie ende i scarp torment "ende ene uerlange[n] quale, ende ene mordeleke doet ende steruende leuen" 
(Beatrijs 34, lin. 93-97). “ ¡Ah, santos deseos de amor, que fuerza cobráis en un alma amante! es una pasión bienaventurada, un agudo tormento, un dolor constante, una muerte terrible y una vida muriendo". Pues finalmente el alma, peregrina en la tierra, no hallará consuelo sino en el país donde reposa Amor. La última parte del séptimo modo muestra pues como el itinerario no tiene por principal objetivo una culminación, sino dar a conocer en siete facetas, en siete imágenes, la experiencia de Amor que "fuera del tiempo" pierde toda estructura lineal y de progreso.

El segundo ejemplo propuesto en este estudio es la carta XX de Hadewijch. A mediados del siglo XIII, aproximadamente por los mismos años en que Beatrijs trabajaba en su tratado y sin que podamos precisar con exactitud ni el momento ni la precedencia, Hadewijch escribía la que conocemos como carta XX. Iba dirigida a una o algunas de sus discípulas. Se trata de un texto breve que en los manuscritos que nos han llegado se encuentra incluido en su epistolario, si bien no contiene encabezamiento epistolar y presenta, como se ha dicho más arriba, la apariencia de un tratado más que propiamente la de una carta. Como ha afirmado Frank Willaert, esta estructura de tratado unida a la brevedad, que se repite en muchas de sus cartas, invitaba probablemente a la meditación y memorización del texto por parte de sus lectoras, algo que se hace especialmente evidente en la número XXIV, estudiada por Willaert, y que describe a través de nueve pasos el peregrinaje al país de Amor (167168). Sea como fuere, la carta $X X$ contiene notables coincidencias con el opúsculo de Beatrijs analizado más arriba, así como aspectos novedosos fundamentales para entender la fusión entre la escalera de perfección y la experiencia de unión en la mística femenina del siglo XIII.

En la carta de Hadewijch nos encontramos de nuevo ante una estructura circular que recorre, en este caso, el transcurso de las 12 horas de una jornada $-\mathrm{o}$, como se ha sugerido y recoge Van Mierlo en el comentario a su edición de la carta, emula los doce signos del zodíaco (Hadewijch, Brieven 168). Las palabras que abren el tratado son tan definitivas y contundentes como las del texto dedicado a los modos de Amor de la priora del Císter e invitan como él a contemplar el giro incesante del caleidoscopio. Escribe Hadewijch al comienzo de su carta: "Die nature daer gherechte minne vte comt die heuet .xij. vren die de Minne berueren vte hare seluen Ende bringhense weder in haer seluen" (Hadewijch, Brieven XX, 170, lin.1-3). "La naturaleza de donde procede el verdadero Amor tiene doce horas que lo arrojan fuera de sí mismo y lo traen luego de vuelta a sí mismo”. Es decir, también aquí se abre ante nosotros un itinerario de perfección que se basa en un círculo y 
que lleva de lo perfecto a lo perfecto, conduciendo al alma por un camino de pasos paralelos escasamente jerárquicos de salida y regreso a Dios. Amor en sí mismo y su acción en el Alma son considerados como una sola cosa. Los diversos tiempos o momentos del desarrollo, que equivaldrían a los modos de Beatrijs, se presentan como doce "horas innombrables" que, a pesar de su inefabilidad, están dramáticamente personificadas. Hadewijch, por tanto, no dice lo mismo que Beatrijs o no lo dice de la misma manera, pero traza con igual vigor al principio de su texto un itinerario circular que, de manera escueta y definitiva, expresa la incomprensible equivalencia de aquello que es a un tiempo semejante y diverso: la experiencia poliédrica de la presencia infinita de Amor en el alma que le lleva a la unión y absorción en la Divinidad de la que había salido.

Antes de abordar la primera hora, Hadewijch explica el sentido de este recorrido circular y de las experiencias acumuladas de Amor. Un sentido sobre el que volverá con palabras muy semejantes en las últimas líneas de la carta. Amor -nos dice- sale de sí mismo expulsado por las doce horas innombrables de su propia naturaleza y al regresar trae consigo todo aquello que le había llevado a salir: "een soekende sen, ende ene begherende herte, Ende ene minnende ziele" (Hadewijch, Brieven XX, 170, lin. 6-8); "un espíritu (sen) que busca, un corazón (herte) que desea y un alma (ziele) amante. Se ha sugerido, como recoge Van Mierlo en su comentario, que el pequeño tratado de Hadewijch quiere, con este comienzo, ordenar la descripción de su itinerario de perfección en tres grandes etapas de cuatro horas cada una (Hadewijch, Brieven 168). Estas etapas recordarían lejanamente la dinámica del progreso espiritual que procede de la tradición desde la patrística: status inchoantium o de los iniciados (de la hora primera a la cuarta), status proficientium o de los que progresan (de la quinta a la octava) y status perfectionis o de los perfectos (de la novena a la duodécima). Un itinerario que seguiría muy de cerca la interpretación de los modos de amor de Beatrijs según la hagiobiografia del capellán de Nazareth que dedica cada uno de los tres libros de su Vita Beatricis a cada uno de los tres estados y que finalmente considera el tratado sobre los modos de Amor como una síntesis de este recorrido (Cirlot y Garí, La Mirada Interior 103 y 114). Pero como sucedía con Beatrijs, el itinerario de Hadewijch, sin que deba negarse la presencia de un progreso espiritual, desborda ampliamente esta estructura, pues las doce horas, que pertenecen a la naturaleza de Amor, son aquí las protagonistas del relato y expresan todas y cada una de ellas por entero la fuerza de Amor que actúa sobre el espíritu, el corazón y el alma. Las doce horas reintegran en Amor todo lo recorrido y el 
recorrido mismo, de modo que a su regreso: "Ende alse Minne dese bringhet, soe worpt sise inden abis der starker naturen, daer Minne vte gheboren es ende gheuoedet" (Hadewijch, Brieven XX, 170, lin. 8-10). "Cuando el Amor trae todo eso, lo arroja al abismo de la poderosa naturaleza de donde él ha nacido y se nutre". El abismo es la naturaleza de Amor desconocida y única, y en él arroja las almas de los amantes en una unidad sin tiempo ni mediación

Dan comen die onghenoemde vren inde onbekinde nature. Dan es Minne te hare seluen comen Ende ghebruket hare naturen beneden hare ende bouen hare ende al omme hare. Ende alle die dan beneden derre kin nessen sijn, hen gruwelt vanden ghenen die daer in gheuallen sijn Ende daer in werken moeten ende leuen ende steruen. Also Minne ghebiedet ende hare nature. (Hadewijch, Brieven XX, 170, lin.10-18) Entonces las horas innombrables pasan a la naturaleza desconocida. Pues Amor ha llegado a sí mismo y disfruta su naturaleza por debajo de él y por encima de él y alrededor de él. Y todos los que permanecen por debajo de esta experiencia, se horrorizan de los que han caído dentro [del abismo] y han de obrar, vivir y morir en él, como Amor y su naturaleza ordenan.

Las doce horas pues forman parte de la naturaleza misma de Amor y se proyectan sobre las almas de formas diversas atrayéndolas y absorbiéndolas en Amor. Tomando cierta distancia respecto a la idea de una escalera de perfección en la que el alma asciende en la práctica de las Virtudes, aquí es Amor quien se manifiesta y en cada una de sus horas ofrece una faceta del prisma de sí mismo, o una de las posibles imágenes del caleidoscopio que se transforma dinámica y constantemente $\mathrm{y}$, al girar, transforma el alma. En este sentido, en el texto de Hadewijch, de forma aun más explícita que en de Beatrijs, la iniciativa procede claramente de Amor, que a lo largo del recorrido despliega sus facetas en doce diversos espejos.

La primera hora parece tener una asociación concreta con la experiencia de la metanoia, con el toque de la gracia que procede de la divinidad y la con-versión del alma hacia Dios. En la primera hora innombrable -escribe Hadewijch-Amor "se manifiesta y toca":

Die eerste onghenoemde vre vanden .xij. die de ziele inder naturen der Minnen trecken dat es: Dat de Minne haer seluen openbaert ende beruert onuersien endeonbeghert, alse mens menst moedet na hare werdecheit, Ende dat sise, soe sterke nature. (Hadewijch, Brieven $\mathrm{XX}, 170$, lin.19-25) 
La primera de las doce horas innombrables que atraen al alma a la naturaleza del Amor es aquella en que Amor se manifiesta y toca, de improviso y sin que lo haya deseado, en el momento más inesperado para ella, a la vista de su condición. Y cuanto más fuerte es su naturaleza en sí misma más incomprensible le resulta [al alma]. Y por eso, es llamada con razón una hora innombrable.

El tacto y la llamada son un tema recurrente en los textos místicos en general y en Hadewijch en particular (Cirlot y Garí, ConTact). En los siete modos de Amor de Beatrijs, el primer modo estaba también marcado por un "deseo activo de amor" que penetra en el alma y que, en la medida en que allí se nos dice que "procede del propio amor" (y no del alma), se entiende como un advenimiento de la divinidad. En la carta XX de Hadewijch, sin embargo, la acción de este con-tacto amoroso en el momento de la conversión indica de manera incontestable una de las formas en que Amor se da a conocer: el "toque" de la gracia divina. Se trata de un concepto que tendrá también un amplio recorrido en la mística posterior. El alma tocada por Dios, de Diez touchee par grace (Marguerite Porete, Mirouer 118, Marguerite Porete, El Espejo 163) constituirá, por ejemplo, el primero de los “estados" de la escalera de la obra de Marguerite Porete. Y en ese mismo sentido hablará Heinrich Seuse de la conversión y de los comienzos del aquel que ha sido "tocado por Dios", imdise indruk von got beschah (Heinrich Seuse, Deutsche Schriften. Leben 8; Heinrich Seuse, Vida 44).

En la segunda hora, Hadewijch plantea la muerte en vida del alma invadida por Amor. "Die ander onghenoemde vre es, Dat de Minne der herten vander starker doot gheuet smake leecheit ende doetse steruen sonder sterfleecheit" (Hadewijch, Brieven XX, 170, lin. 26-28). "La segunda hora innombrable es aquella en que Amor hace saborear al corazón una tremenda muerte. Lo hace morir sin que le sea posible morir". Sin duda, la expresión "morir sin morir" recuerda la del tercer y séptimo modo de amor de Beatrijs, en los que se habla de la muerte en vida del alma que vive en el exilio de Amor, pero recuerda también la laude de Ángela da Foligno que en el séptimo paso exclama: "ideum meo vivere est mori" (Ángela da Foligno 365), "por lo que mi vivir es morir". En todo caso, el foco en la carta XX está puesto de nuevo con claridad en la acción de Amor mismo y en la relación sensorial que éste provoca en el alma o, mejor dicho, y en correspondencia con su omnipresencia en la espiritualidad cisterciense, en el corazón: es Amor quien procura la muerte en vida y es él quien se la hace "saborear" al corazón en esta segunda hora innombrable, después de haberlo "tocado" en la primera. 
Estrechamente unida a la segunda hora y casi como una extensión de la misma, aparece también la tercera: "Die derde onghenoemde vre es, Dat de Minne doet leren bi wat saken datmen steruen ende leuen mach in hare, ende openbaert datmen || niet Minnen en mach sonder grote pine" (Hadewijch, Brieven XX, 170, lin.32-35). "La tercera hora innombrable es aquella en que Amor enseña que se puede morir y vivir en él y revela que no se puede amar sin grandes sufrimientos". El sufrimiento seguía perteneciendo en el caso de Beatrijs al segundo modo de Amor y era identificado como Infierno. En la tercera hora, para Hadewijch, quien como se ha visto también le da el nombre de Infierno a Amor en uno de sus poemas, el sufrimiento es descrito como una más de las enseñanzas de Amor y una de sus formas de hacerse presente en el alma.

En la cuarta hora innombrable, el alma acepta de Amor "hare verhoelne ordele die diepere ende donckere sijn dan die afgronde" (Hadewijch, Brieven $\mathrm{XX}, 170$, lin. 36-39); "sus juicios secretos, que son más profundos y oscuros que los abismos", sin conocerlos ni comprenderlos. Una vez más, los "saborea" (smake) por obra de Amor, sin experimentar, sin embargo, en esta "hora" su esencia. La aceptación en el desconocimiento es paradójicamente presentada como una faceta del prisma de Amor, es decir, como una más de sus caras y de sus obras.

En la quinta hora, por el contrario, el alma seducida por Amor sale de sí para habitar en la naturaleza de Amor. Escribe Hadewijch "Ende dan verliest si dat wonderen vander cracht Ende de donkerheit vanden ordele, ende verghet der pinen vander Minnen. Ende dan en kintse de Minne niet in ghene nature dan slechs in Minnen" (Hadewijch, Brieven XX, 171-172, lin. 47-51). "Y entonces el alma pierde su estupor ante la fuerza [de Amor] y la oscuridad de sus juicios y olvida las penas de Amor. Y no experimenta a Amor de otra manera que en Amor mismo". Curiosamente, la carta afirma que esto, "dat schijnt ene nederheit ende en es niet" (Hadewijch, Brieven $\mathrm{XX}, 172$, lin. 51-52), "aunque parece un retroceso no lo es", insinuando que una mayor cercanía empobrece la visión de lo que se está alcanzando al acercarse al umbral: "alse men alre naest soude kinnen, datmen dan der kennissen alre slechst es" (Hadewijch, Brieven XX, 172, lin. 53-55); "cuando se conoce de más cerca, también se es más pobre en conocimiento". Esta afirmación permite plantear la idea de que en el transcurso de las horas innombrables una de las caras del prisma de Amor es el umbral. Un umbral que debe atravesar el Alma y que no habla de la conversión por la gracia ni del juego amoroso, sino de la transformación misma del alma en Amor. Sin 
precisar momentos ni etapas concretas, y sin perder nunca el horizonte de diversidad y equivalencia entre los modos de Amor, la quinta hora permite intuir una cesura donde el alma abandona sus referentes de sentido para vivir en Amor. Años más tarde, otra beguina, Marguerite Porete, en su escalera de perfección que de nuevo se ve desbordada en múltiples momentos por las paradojas de su propio significado, dirá algo muy similar. En su obra, Le mirouer des simples âmes, Marguerite enseña que en el ascenso el alma cae y al caer atraviesa el umbral entre Razón y Amor. Se trata de la "Caída de las Virtudes en Amor "y del paso del alma del dominio de Razón al dominio de Amor (Garí 222-223; Muraro 183).

Quizá esta comparación de la carta XX de Hadewijch con el libro de Marguerite ayude a entender mejor la hora que sigue a esta quinta. La sexta hora innombrable es aquella en la que el Amor, que invade el alma y le ha hecho atravesar el umbral, le hace abandonar el régimen de Razón por el desbordamiento constante de Amor mismo:

Die seste onghenoemde vre es, Dat Minne versmadet redene ende al dat in redenen es, ende daer bouen ende daer onder/. Wat dat ter redenen behoert, dat es al ieghen saluut der gherechter. naturen der Minnen/: Want redene en mach der Minnen nemen noch gheuen; Want gherechte redene der Minnen, dats altoes ene wassende vloet sonder peys ende sonder vergheten. (Hadewijch, Brieven XX, 172, lin. 56-63) La sexta hora innombrable es aquella en que Amor desprecia a Razón y todo lo que hay en ella, por encima de ella, y por debajo de ella. Cuanto pertenece a Razón es contrario a la verdadera naturaleza de Amor. La Razón no puede quitar ni dar nada a Amor. Pues la auténtica razón de Amor es un desbordamiento creciente sin tregua ni suspensión.

Siguiendo esta misma lógica, la séptima hora dibuja los límites entre la escalera ascendente de la práctica de las Virtudes y la obra de Amor. La experiencia de la séptima hora innombrable es de nuevo háptica (Cirlot y Garí, ConTact). El toque es ahora el nombre más secreto de Amor. "Die seuende onghenoemde vre es, dat gheen dinc wonen en mach in de Minne noch hare en mach gheen dinc gherienen sonder begherte Ende hare verborghenste name dat es ghereinen" (Hadewijch, Brieven XX, 172, lin. 64-67). "La séptima hora innombrable es aquella en que nada puede vivir en Amor y nada le puede tocar salvo el deseo, cuyo nombre más secreto es toque, una fuerza que brota de Amor mismo". Si el toque de la gracia transformaba al alma y 
la lanzaba a la aventura de Amor, ésta siente ahora con todos sus sentidos espirituales la fuerza de Amor por el que es tocada. En este juego amoroso, Amor se encuentra por encima de todas las Virtudes:

Nochtan es si in haer seluen al volmaect.Minne mach wonen in alle dinc. De Minne mach wonen in caritaten, Mer caritate en mach niet wonen in Minnen. Jn Minne en mach wonen ontfermicheit, noch ghe- nadicheit, Noch oetmoedicheit, Noch redene, Noch vrese/, Noch sparen/, Noch mate, Noch gheen dinc. Mer in al dese woent Minne, Ende alle dese werden vte Minnen gheuoedet. (Hadewijch, Brieven XX 172, lin.70-78)

Amor es completamente perfecto en sí mismo. Amor puede habitar en todas las cosas. El Amor puede habitar en Caridad, pero Caridad no puede habitar en Amor. En Amor no pueden habitar ni Misericordia, ni Clemencia, ni Humildad, ni Razón, ni Temor, ni Discreción, ni Medida ni otra cosa; pero en todas ellas habita Amor y todas son nutridas en Amor. Pero él mismo no recibe alimento más que de su propia totalidad.

El Amor habita pues las Virtudes pero estas no son iguales a Amor, una afirmación que recuerda de nuevo el doble sistema referencial que establecerá años más tarde el Mirouer, y su argumento acerca de la maternidad y superioridad de Amor sobre todas las Virtudes, así como su identidad con Dios. La consecuencia es el canto de despedida de las Virtudes entonado en el Espejo por el Alma libre que vive en Amor y es Amor mismo (Garí "Introducción" 22-24). Es necesario admitir que en relación con este tema en la obra de Marguerite Porete resuenan con claridad los ecos de la carta XX de Hadewijch.

La octava hora es la del rostro de Amor. La visión del rostro es un tema recurrente en la obra de Hadewijch y aquí aparece en el centro del proceso de conocimiento amoroso. Die achtende onghenoemde vre es, Dat der Minnen nature in haer anschijn es alre wonderleecst te kinnenne (Hadewijch, Brieven XX, 172, lin.81-83). "La octava hora innombrable es aquella en que la naturaleza de Amor en su rostro es el conocimiento más sorprendente". En la vida cotidiana, explica Hadewijch, el rostro es lo primero que se ve y conoce, pero en Amor es lo más recóndito y secreto. Con todo, retornando a la imagen del caleidoscopio, la contemplación del rostro de Amor no es un punto de llegada o de culminación del itinerario espiritual, sino un instante sin tiempo en el girar incesante de las horas inefables que manifiestan la naturaleza de Amor. 
Por su parte la novena hora es la tormenta (storme) de Amor que asola brutalmente y absorbe tiernamente al alma: Die neghende onghenoemde ure es, Daer Minne es in haren staercsten storme Ende in haren scaerpsten ontmoete Ende in haren diepsten besoekene, daer es hare anschijn alre suetst Ende alre ghemackeleecst ende alre minleecst (Hadewijch, Brieven XX, 172, lin. 88-92). "La novena hora innombrable es aquella en que Amor se encuentra en su más feroz tormenta, en su asalto más impetuoso, en su más profunda incursión. Pero su rostro es dulcísimo, lleno de paz y suprema amabilidad y muestra inmensa ternura".

La tormenta (storme) y la furia (orewoet) son conceptos clave en la obra de Hadewijch para expresar la acción de Amor en el alma. En paralelo, los ecos del quinto modo de amor de Beatrijs se escuchan en estas líneas. En Beatrijs la tempestad, el estrépito y el furor de Amor asaltaban al alma en el quinto modo y al tiempo la abrazaban. En medio de la violencia amorosa, Amor hería una y otra vez el corazón, atravesándolo con una flecha. También ahora, en la novena hora innombrable de Hadewijch, la herida de Amor comparece en medio de la tormenta y la ternura, pues Amor: soe si dieper wondet dien daer si op stormt, soe si metter werdicheit van haren anschine dien si mint sachtere in hare seluen verdrinket (Hadewijch, Brieven XX, 172, lin. 93-96); "cuanto más profundamente hiere a quien asalta, con mayor dulzura absorbe en sí mismo, con la nobleza de su rostro, a aquel que ama". Sabemos por otros textos de la propia Hadewijch, especialmente el decimotercer poema estrófico, que la herida a la que se refiere aquí es, como en el tratado de Beatrijs, la de la flecha de Amor. Este poema habla precisamente de la herida causada por las flechas de Amor minen trole en el alma noble, y vuelve una y otra vez sobre el tema. Así, por ejemplo, en la tercera estrofa nos dice: In Allen tide alse ruert die strale, meeret hi die wonde (Hadewijch, Liederen 13, 132) "Cada vez que la flecha golpea, agranda la herida".

La décima hora muestra al Amor soberano, injuzgable y juez ante el que todo comparece. Equiparado a la Deidad, Amor clama con voz potente la orden de amar a los amantes: Die stemme maect soe grote cracht, si ludet van onghehoertheiden vreseleker dan de donder (Hadewijch, Brieven XX, 172, lin.106-108). "Esa voz es tan ensordecedora e inaudita que resuena más terrible que el trueno". Y esa voz es al mismo tiempo "lazo", "espada", "vara" y "magisterio" con que instruye a sus discípulos. Confluyen en estas líneas muchos de los conceptos clave que la beguina acuña para nombrar a Amor en sus poemas, cartas y visiones. La función de todos ellos es el magisterio, la Minnen scole, la "escuela de Amor" en la que se instruye el alma. Como se 
dirá también en el poema decimotercero: Maer die met waerheiden in minnen dichten ende met claerre redenen dan verlichten, daer sal de minnehare escole in stichten. Diede selen meestere wesen ende ontfaender minnen hoechste ghichten, die wonden sonder ghenesen (Hadewijch, Liederen 13, 136); “en aquel que escribe con verdad sobre el Amor y es iluminado con la razón clara, Amor funda su escuela: Serán maestros y recibirán los más altos dones de Amor que inflige heridas incurables".

En la undécima hora innombrable, el que ama, poseído totalmente por Amor, se hace simple. Ni Beatrijs en su tratado, ni aquí Hadewijch, usan este concepto, "simple", que encontrará su perfecta formulación en Marguerite, pero la descripción de cómo el amor hace una la memoria (memorie) del amante permite recoger precisamente esa idea, la del alma simple anonadada en amor. Como hemos visto, en las primeras líneas de la carta XX, al explicar el sentido general del itinerario de perfección, Hadewijch cerraba el círculo cuando Amor regresaba a sí mismo llevando consigo un espíritu (sen) que busca, un corazón (herte) que desea y un alma (ziele) amante. En la undécima hora se nos muestra a Amor poseyendo con violencia a quienes ama, de forma que ni el espíritu puede apartarse, ni el corazón desear, ni el alma amar fuera del propio Amor. En este estado de unión: Die minne maect sine memorie soe enech dat hi ghe-dinken en can omme heyleghen Noch omme menschen, Noch dies hemels, Noch dier erden, Noch der Jnghele, Noch sijns selues, Noch gods (Hadewijch, Brieven XX, 172, lin. 117-120); "el amor unifica su memoria a tal punto que este ya no puede pensar en los santos, ni en los hombres, ni en el cielo, ni en la tierra, ni en los ángeles, ni en sí mismo, ni en Dios”. Las palabras del sexto modo de Beatrijs, cuando describe al alma libre y en reposo en la unidad de Amor, regresan a nuestros oídos y sorprenden por la cercanía con la que ambos tratados expresan la total absorción en Amor. Como para Hadewijch, también para la priora cisterciense, tal como hemos visto más arriba, en el sexto modo el alma se ha hecho tan audaz "que no teme ni hombre ni demonio, ni ángel ni santo, ni a Dios mismo". Ellas dos no serán las únicas en expresar con estas palabras u otras semejantes el anonadamiento del alma. Unas décadas más tarde, Marguerite Porete recogerá en su Miroir una idea cercana a esta. En el capítulo 81, hablando del alma simple, libre y anonadada totalmente en Amor, pone en boca del propio Amor lo siguiente: "Or a cese Ame, dit Amour, son droit non du nient en quoy ell demoure. Et puisque elle est nient, il ne luy chault de nient, ne d'elle ne de ses proesmes ne de Dieu mesmes" (Margherite Porete, Mirouer 230). "Esta Alma-dice Amor- recibe su verdadero nombre de la nada donde mora. Y puesto que 
ella es nada, no le importa nada, ni ella misma, ni su prójimo, ni el propio Dios" (Marguerite Porete, El Espejo 130).

El tratado de Hadewijch llega así a la duodécima y última de las horas. En ella Amor se basta a sí mismo: "Hare name dat es hare wesen binnen hare. Hare name sijn hare werken buten hare. Haer name es haer crone bouen hare. Hare name dats hare gront onder hare" (Hadewijch, Brieven XX, 174-175, lin. 130-134). "Su nombre es su esencia dentro de él. Su nombre son sus obras fuera de él. Su nombre es su corona encima de él. Su nombre es su hondura bajo de él". El círculo se cierra. Por eso, puede decirse, como del séptimo modo del tratado de Beatrijs, que la duodécima hora es todas y superior a todas, subrayando al mismo tiempo la idea de itinerario y de totalidad de cada una de las horas innombrables. En esta última, Amor: "daer eerst springhet vte hare seluen Ende si werket met hare seluen, Ende si es soe sinckeleec in hare seluen" (Hadewijch, Brieven XX 174-175, lin. 124-126), "escapa de sí mismo y obra por sí mismo y regresa siempre a sí mismo". Todo el itinerario está por tanto completamente integrado en él.

En las últimas líneas del tratado, Hadewijch vuelve sobre sus propios pasos para recoger una vez más el sentido global del círculo de salida y regreso de Amor a Amor, y del alma a la Divinidad, planteado al comienzo. En las primeras líneas de su carta Hadewijch describía cómo al regresar Amor lanzaba al abismo de su naturaleza cuanto traía consigo, afirmando que quien no ha experimentado a Amor se horroriza de los que han caído dentro del abismo y han de obrar, vivir y morir en él. Ahora, al finalizar su carta, Hadewijch, al igual que Beatrijs, recapitula:

Dit sijn de .xij. onghenoemde vren der Minnen; want in ghene vre van desen .xij. en can men der Minnen Minne verstaen, Dan die ic seide die inden abys der starcker naturen der Minnen gheworpen sijn ochte die daer toe behoren. Die dat sijn, die ghelouenre vordere in dan sij verstaen. (Hadewijch, Brieven XX, 175, lin. 135-140)

Estas son las doce horas innombrables de Amor. Pues en ninguna de estas doce horas puede nadie comprender el amor de Amor, excepto aquellos que, como he dicho, han sido lanzados al abismo de la poderosa naturaleza del Amor, o los que están destinados a ello. Estos últimos creen más que comprenden.

La lectura y el estudio del tratado de Beatrijs y de la carta XX de Hadewijch nos permiten plantear finalmente algunas reflexiones de carácter general y nos conducen a ciertas conclusiones. Ambos tratados son diferentes. Más 
sistemático probablemente el de Beatrijs, más cargado de una poderosa fuerza poética que arrasa el texto en el caso de la carta de Hadewijch. Quizás también el momento de escritura, el objetivo y el público al que ambos se dirigían ayuda a marcar las diferencias. Pero sin lugar a dudas, al recorrer cada uno de los momentos, modos, imágenes o experiencias de Amor, en ambos textos se ponen de manifiesto muchos elementos de semejanza. Por un lado, existe -y eso es algo bien sabido- un vocabulario común que aporta en ambas autoras novedades importantes para la espiritualidad del siglo XIII; conceptos e imágenes se entrecruzan en sus escritos y nos dejan intuir la cercanía de pensamiento y experiencia que se esconde en la obra de ambas. Pero, por otro lado, en relación con el interrogante que nos hemos formulado aquí, se hace evidente que ambos tratados plantean de manera significativa una misma cuestión y la resuelven de forma semejante. 1.- En primer lugar, los siete modos de Amor de Beatrijs y la carta XX de Hadewijch describen, sin que quepan dudas, un itinerario espiritual. En ambos, a modo de trasfondo, se intuye un recorrido ascensional por escalones, no ajeno a un cierto ejercicio de las Virtudes que permite al alma el ascenso hacia Dios. Pero tanto uno como otro texto están muy lejos de poder reducirse a una escalera que remonta hacia el cielo a través de un proceso de práctica devocional, de purificación y de perfección. 2.- En segundo lugar, ambos textos toman como punto de partida y base de su recorrido un tema fundamental en la espiritualidad medieval: el lazo neoplatónico de salida y regreso a la divinidad, trazando un círculo que lleva de lo perfecto a lo perfecto. 3.- En tercer lugar, en ambos, el protagonista es Amor que se identifica en su naturaleza con la Divinidad y que actúa en el Alma. Con todo, cabe señalar que el enfoque de uno y otro texto muestra una perspectiva algo distinta: en Beatrijs, la experiencia narrada hace especial hincapié en el Alma y en la acción de Amor sobre ella, la cual, recorriendo el itinerario circular, aprecia sucesiva y simultáneamente siete experiencias de Amor que conducen a la unión; en Hadewijch, el planteamiento es más radical y, al menos narrativamente, es Amor el que sale y regresa atravesando doce horas inefables que le pertenecen, llevando consigo y reintegrando en sí mismo cuanto ha encontrado a su paso y lanzando al abismo de su naturaleza a sus amantes. 4.- Pero, en cuarto lugar, una y otra forma de aproximación conducen a un terreno semejante: el Alma -el corazón y el espíritu- de los amantes es la que experimenta la obra de Amor en modos y facetas diversas hasta con-fundirse en él en una unión amorosa. 5.- En quinto y último lugar, ambas autoras cierran el círculo, en el séptimo modo y en la hora duodécima respectivamente, describiendo una experiencia de Amor que en cierta manera 
es, aun presentándose como culminación, todos los modos u horas al mismo tiempo, pues recoge e integra en sí misma el recorrido trazado a través de los diferentes estados o momentos. Y puede hacerlo porque definitivamente ese cierre es concebido como un instante sin tiempo".

Quizá tengamos ahí la clave para interpretar estos y otros textos del nuevo misticismo articulados en algún grado en forma de itinerario espiritual: si se trata en última instancia de una experiencia fuera del tiempo, el trazado lineal y sucesivo, que necesariamente se despliega en el tiempo y que se encierra bajo la noción de escalera o de itinerario ascensional de perfección a lo largo de una vida, no basta. Sin abandonarla por completo, a esa imagen hay que añadirle otra que surge de una experiencia que no pertenece al régimen de lo temporal y que permite concebir el conjunto del itinerario de una forma nueva. En ella, las bellas imágenes poéticas que buscan poner en palabras la presencia inefable de Amor giran sin principio ni fin en un caleidoscopio espiritual que, sin negar la escalera, la desborda.

\section{BIBLIOGRAFÍA}

\section{FUENTES PRIMARIAS}

Ángela de Foligno. Libro de la experiencia. Ed. y trad. Pablo García Acosta. Madrid: Siruela, 2014.

Beatrijs van Nazareth. Seven manieren van minne. Ed. Léonce Reypens en Jozef van Mierlo, DBNL http://www.dbnl.org/tekst/beat0011rey01_01/beat001lrey01_01_0003.php [consulta 07/08/2018]

Hadewijch. Visioenen. Ed. Jozef van Mierlo. Antwerpen, Gent, Mechelen: De Vlaamsche Boekenhalle, 1924-1925. https://www.dbnl.org/tekst/hade002visi01_01/

Mengeldichten, Ed. Jozef van Mierlo. Antwerpen: Standaard-Boekhandel, 1952. https://www.dbnl.org/arch/hade002jvan04_01/pag/hade002jvan04_01.pdf

Brieven. Ed. Jozef van Mierlo. Antwerp: Staandard, 1947. DBNL 2003: http:// www.dbnl.org/tekst/hade002brie01_01/colofon.htm

Das Buch der Visionen. Ed. y trad. Gerald Hofmann, "Mystik in Geschichte und Gegenwart”. Stuttgart-Bad Cannstatt: Fromman Holzboog, 1998.

Liederen. Ed.Veerle Fraeters y Frank Willaert. Groningen: Historische Uitgeverij, 2009.

Heinrich Seuse. Deutsche Schriften. Im Auftrag der Württembergischen Kommission für Landesgeschichte. Ed. Karl Bihlmeyer. Stuttgart,1907 (reedición, Minerva, Fráncfort del Meno, 1961).

Vida. Ed. y trad. Blanca Garí. Madrid: Siruela, 2012. 
Marguerite Porete. Le mirouer des simples âmes. Margaretae Porete Speculum simplicium animarum. Ed. Romana Guarnieri y Paul S. J. Verdeyen. Corpus Christianorum, Continuatio Medievalis LXIX. Turnhout: Brepols, 1986.

El Espejo de las almas simples. Ed. y trad. Blanca Garí. Madrid: Siruela, 2005.

Vita Beatricis. De autobiografie van de Z. Beatrijs van Tienen O. Cist. 1200-1268. Ed. L. Reypens Antwerpe, Ruusbroecgenootschap, 1964.

\section{FUENTES SECUNDARIAS}

Acosta-García, Pablo y Anna Serra Zamora. "Apophatic Mountains: Poetics of Image in Marguerite Porete and John of the Cross". Viator 48-1 (2017): 253-274.

Cirlot, Victoria. "La ciudad celeste de Hildegard von Bingen". Anuario de Estudios Medievales 44/1 (enero-junio de 2014): 475-513.

Cirlot, Victoria y Blanca Garí. La mirada interior. Escritoras místicas y visionarias de la Edad Media. Madrid: Siruela, 2008.

ConTact. Tactil experiences of the sacred and the divinity in the Middle Ages (en preparación).

Garí, Blanca. "Introducción”. Marguerite Porete. El Espejo de las almas simples. Ed. y trad. Blanca Garí. Madrid: Siruela, 2005. 9-36

"Marguerite Porete y la Biblia. Imágenes de la kenosis en el Espejo de las almas Simples". Critica del Testo Rivista del Dipartimento di Studi Europei. Sapienza Uni. Roma, Vol: XV - 1 (2012): 217-236.

Haas, Alois Maria. "Beatrijs van Nazareth (um 1200-1268)". Geistliches Mittelalter. Friburgo: Universitätsverlag, 1984. 393-397.

Heck Christian. L'échelle céleste dans l'art du Moyen Age: une image de la quête du ciel. Paris: Flammarion, 1997.

Hollywood, Amy. The Soul as Virgin Wife. Mechthild of Magdeburg, Marguerite Porete and Meister Eckhart. Notre Dame: Indiana University of Notre Dame Press, 1995.

Jung, Carl Gustav. Recuerdos, sueños, pensamientos. Barcelona: Seix i Barral, 1964 (1 ${ }^{\mathrm{a}}$ edición, Zúrich, 1962).

McGinn, Bernard. The Presence of God. A History of Western Christian Mysticism, vol. III, The Flowering of Mysticism. Men and Women in the New Mysticism, 1200-1350. Nueva York: Crossroad, 1998.

Muraro, Luisa. "Pace di carità in vita annientata: la scoperta di Margherita Porete. Luisa Muraro. Le amiche di Dio. Napoli: D’Auria, 2001. 181-203.

Spitzlei, Sabine B. Erfahrungsraum Herz. Zur Mystik des Zisterzienserinnenklosters Helfta im 13. Jahrhundert. Stuttgart-Bad Cannstatt: Frommann-Holzboog, 1991.

Willaert, Frank. "Peregrinos al País del Amor. Mistagogía y Memoria en Hadewijch de Brabante". Revista Chilena de Literatura 62 (2003): 165-182. 